\title{
En Yüksek Piyasa Değerine Sahip On Kripto Paranın Birbirleriyle Etkileşimi
}

\author{
Gökben ADANA KARAAĞAÇ* \\ Serpil ALTINIRMAK ${ }^{* *}$
}

\section{$\ddot{O Z Z E T}$}

Çalışmada gün geçtikçe popülerliği ve buna bağll olarak toplam piyasa değerleri ve işlem hacimleri artan, çok sayıla ve çok çeşitli piyasalarda işlem gören kripto paraların fiyatlarının birbiri üzerindeki etkisi araştırılmıştır. Çalışmada, Bitcoin, Ethereum, Ripple, Bitcoin Cash, Cardano, Litecoin, NEM, NEO, Stellar ve IOTA kripto paralarının seçiminde toplam piyasa değerleri dikkate alınmıştır ve en yüksek toplam piyasa değerine sahip 10 kripto para analize dahil edilmiştir. 15 Arallk 2017 ve 17 Ocak 2018 tarihleri arasında çalışmaya konu olan kripto paraların günlük fiyat hareketleri arasındaki ilişkiyi incelemek için serilere Johansen Eşbütünleşme Testi ve Granger Nedensellik Testi uygulanmuştır. Çalışmanın sonucunda, Cardano'nun NEO'nun Granger nedeni olduğu, Bitcoin'in Bitcoin Cash'in Granger nedeni olduğu, Litecoin'in Bitcoin Cash'in Granger nedeni olduğu, NEM'in Bitcoin Cash'in Granger nedeni olduğu, Ripple'ın Bitcoin'in Granger nedeni olduğu, NEO ve Ethereum'un birbirinin Granger nedeni olduğu, NEO ve Litecoin'in birbirinin Granger nedeni olduğu ve NEM'in Stellar'in Granger nedeni olduğu tespit edilerek, bu değişkenlerin fiyat hareketlerinin klsa dönemde birbirini etkilediği ortaya konmuştur.

Testi.

Anahtar Kelimeler: Blockchain Teknolojisi, Kripto Paralar, Johansen Eşbütünleşme Testi, Granger Nedensellik

JEL Sinıflandırması: C12, G11, G15.

\section{Interaction between Ten Cryptocurrencies which Have the Highest Market Capitalization}

ABSTRACT

In this study, we investigated the influence of the cryptocurrencies' prices on each other, which are known more and more every day, and which are increasing in transaction volume and traded in various markets. These cryptocurrencies are; Bitcoin, Ethereum, Ripple, Bitcoin Cash, Cardano, Litecoin, NEM, NEO, Stellar and, IOTA. Johansen Cointegration Test and Granger Causality Test were applied to the series. In order to examine the relationship between the daily price movements of cryptocurrencies, which is the subject of the study between December 15, 2017 and January 17, 2018. The result of the analyses show that Cardano Granger causes NEO, Bitcoin Granger causes Bitcoin Cash, Litecoin Granger causes Bitcoin Cash, NEM Granger causes Bitcoin cash, Ripple Granger causes Bitcoin, NEO and Ethereum have a bidirectional causality relationship with each other, NEO and Litecoin also exhibit a bidirectional causality relationship with each other, and NEM Granger causes Stellar, the results prove that the price movements of these variables affect each other in the short run.

Keywords: Blockchain Technology, Cryptocurrencies, Johansen Cointegration Test, Granger Causality Test.

Jel Classification: C12, G11, G15.

\footnotetext{
* Gökben Adana Karaağaç, Anadolu Üniversitesi, Sosyal Bilimler Enstitüsü, gokbenkaraagac@ gmail.com

** Doç. Dr. Serpil Altınırmak, Anadolu Üniversitesi, Eskişehir Meslek Yüksekokulu, saltinirmak@anadolu.edu.tr
} 


\section{GíRiş}

Günümüzde teknolojideki önüne geçilemez hızlı gelişim bütün dünyayı etkilediği gibi, ülkelerin finansal sistemlerini ve finansal piyasalarını da etkisi altına alarak bu piyasalarda kullanılan araçlarda da çeşitlenmeye ve değişikliklere neden olmuştur. Teknolojideki bu gelişime paralel olarak, geleneksel anlamdaki para yerini artık sanal para kullanımına bırakmaya başlamıştır. Özellikle 2009 yılında Bitcoin'in kullanılmaya başlanmasıyla birlikte, günümüze kadar olan süreçte kripto paralara olan ilgi bir hayli artmış ve başta Bitcoin olmak üzere sanal paraların işlem hacimlerinde ve piyasa değerlerinde de büyük oranlarda artış gözlemlenmiştir.

Klasik ekonomide paranın tanımı yapılırken üç temel özelliği taşıması gerektiği söylenir. Bunlar; değişim arac1 olması, değer saklama arac1 olması ve hesap birimi olmas1 özellikleridir (Wandhöfer, 2017: 248). Geleneksel paranın fonksiyonlarından yatırım ve tasarruf aracı olma özelliğini taşıyan Bitcoin'i, bazı kesimler para olarak kabul ederken bazı kesimler bu konu üzerinde hala tartışmalarını sürdürmektedir. Bitcoin'in yasal düzenlemelere tabi olmaması ve merkezi bir otorite tarafindan kontrol ediliyor olmaması da onu geleneksel anlamdaki paradan ayıran özelliklerindendir (Wandhöfer, 2017: 248).

İşlem görmeye başlayan ilk kripto para olan Bitcoin, halihazırda en yüksek işlem hacmine de sahip olanıdır. Yatırımcılar kripto paraları da bir yatırım aracı olarak kabul etmeye ve geleneksel anlamdaki yatırım araçlarından sonra, kripto paralara da yatırım yapmaya başlamışlardır. $\mathrm{Bu}$ nedenle bu para birimleri arasındaki etkileşim de yatırımcı açısından dikkat edilmesi gereken bir husus haline gelmiştir.

Kripto paralar ile ilgili yapılan akademik çalışmaların temelini Bitcoin ile ilgili olanlar oluşturmaktadır. Bitcoin ile ilgili verilere 2010 tarihinden itibaren ulaşılmaya başlanmıştır. Bu tarihten itibaren yeni kripto paralar piyasalarda işlem görmeye başlayana kadar geçen sürede çalışmalar Bitcoin üzerinde yoğunlaşmıştır. Fakat gün geçtikçe kripto paraların çeşitliliğindeki, piyasa değerindeki, işlem hacmindeki, işlemlerin gerçekleştiği piyasalardaki ve konuya ilgi duyan yatırımcı ve araştırmacıların sayısındaki artışla birlikte, Bitcoin ile beraber diğer kripto paralar ile ilgili yapılan akademik çalışmaların sayısında da artış meydana gelmiştir ve konu bazı araştırmacıların çalışmalarına da konu olmuştur.

Kristoufek (2014) çalışmasında, Bitcoin fiyatlarını etkileyen olası faktörleri spekülatif ve teknik açıdan incelemiş ve bunun Çin piyasalarındaki olası etkilerini araştırmıştır. 14.9.2011 ve 28.2.2014 tarihleri arasında Bitcoin fiyat endeksi, döviz kuru, finansal bask1 endeksi (financial stress index), altın fiyatları gibi değişkenlerin dalgacık (wavelet) modeli ile incelendiği çalışmada, Bitcoin'in hem standart, hem de spekülatif özelliklere sahip kendine özgü bir finansal varlık olduğu ve ayrıca Çin Bitcoin piyasalarında gerçekleşen olayların ABD Dolar piyasaları üzerinde önemli bir etkisi olduğu sonucuna varılmıştır.

Dwyer (2015) çalışmasında, altın, döviz ve Bitcoin'in getirilerinin oynaklığını araştırmıştır. Bitcoin aylık getirilerinin oynaklığının hem altın hem de bazı para birimlerinin getirilerinin oynaklığından daha yüksek olduğunu tespit etmiştir.

Atik vd. (2015) çalışmalarında, Bitcoin fiyatları ile geleneksel döviz piyasaları arasındaki ilişkiyi Granger nedensellik analizi ile test etmişlerdir. Bu amaçla 2009 ve 2015 yılları arasında Bitcoin'in günlük fiyatları ile dünya piyasalarındaki öncü çapraz kur fiyatları arasındaki etkileşim incelenmiş ve Bitcoin ile Japon Yen'inin birbirlerini gecikmeli olarak etkilediği ve Japon Yen'inden Bitcoin'e doğru tek yönlü bir nedensellik ilişkisinin varlığı tespit edilmiştir. 
Dyhrberg (2016) çalışmasında, finansal varlık olma özelliklerini taşıma açısından Bitcoin, altın ve doların benzerliklerini GARCH modellerini kullanarak 19 Temmuz 2010 ve 22 Mayıs 2015 tarihleri arasındaki Bitcoin fiyat verilerini Coindesk Endeksi'nden elde ederek araştırmıştır. Analiz sonucunda, Bitcoin' in altın ve dolar ile birçok benzerliğe sahip olduğu ve Bitcoin'in bir para birimi gibi federal fon oranlarına önemli ölçüde tepki verdiği ortaya konulmuştur.

Sahoo (2017), bir kripto para birimi olan Bitcoin'in büyüme hızı ve volatilitesini ölçmek amacıyla yaptığı çalışmasında, 17 Ağustos 2010 ve 29 A ğustos 2017 tarihlerini kapsayan süreçte ARCH ve GARCH modellerini kullanmıştır. Büyüme hızı, haftalık bazdaki işlem hacimleriyle, volatilite ise haftalık bazdaki fiyat dalgalanmalarıyla ölçülmüştür. GARCH sonuçlarına göre Bitcoin'in volatilitesinin oldukça yüksek olduğu sonucuna varılmıştır.

Balcılar vd. (2017) çalışmalarında, Bitcoin'in işlem hacmi, getirileri ve oynaklığ arasındaki nedensellik ilişkisini test etmişlerdir. 19 Aralık 2011 ve 25 Nisan 2016 tarihleri arasındaki verilerle yapılan analiz sonucunda, ayı ve boğa piyasalarında Bitcoin'in işlem hacminin, getirilerini tahmin etmede kullanılabileceğini ortaya koymuşlardır.

Li ve Wang (2017) teoriye dayalı olarak yaptıkları ampirik çalışmalarında, teknolojik ve ekonomik faktörler çerçevesinde, Amerikan Doları karşısında Bitcoin kurunun belirlenmesini amaçlamışlardır. ARDL modeli ile durağan ve durağan olmayan zaman serileri bir arada kullanılarak tahminler yapılmıştır. Analiz sonuçlarına göre kısa dönemde Bitcoin kurunun ekonomik koşullar ve piyasa koşullarına uyum sağladığı, uzun dönemde ise Bitcoin kurunun ekonomik koşullara karşı daha duyarlı olduğu fakat teknolojik faktörlere daha az duyarlı olduğu tespit edilmiştir.

Katsiampa (2017) çalışmasında, Bitcoin fiyatlarındaki oynaklığı tespit etmede hangi GARCH modelinin en iyi sonucu verdiğini araştırmıştır. 18.7.2010 ve 1.10.2010 tarihleri arasında Bitcoin'in günlük kapanış fiyatlarının kullanıldığı çalışmada 2267 adet günlük veri analize dahil edilmiştir. Çalışmanın sonuncunda Bitcoin fiyatlarının oynaklığını tespit etmede AR-CGARCH modelinin en iyi sonucu verdiği tespit edilmiştir.

Ciaian vd. (2018) çalışmalarında, Bitcoin ve çalışmaya konu olarak seçilmiş 16 alt coin piyasası arasındaki ilişkiyi ve birbirleri ile olan bağımlılıklarını kısa ve uzun dönem açısından ayrı ayrı incelemişlerdir. 2013 ve 2016 yılları arasındaki dönemde işlem gören 17 adet kripto para, piyasa değerlerine göre seçilmiştir. ARDL modelinin uygulandığı çalışmada, Bitcoin ve alt coinler arasında bir fiyat ilişkisi olduğu ve bu ilişkinin kısa dönemde uzun döneme göre daha güçlü olduğu tespit edilmiştir.

\section{BLOCKCHAIN TEKNOLOJISI, KRİTO PARA BİRIMLERİ VE BITCOIN}

Blockchain kelimesinin Türkçe karşılığı "blok zinciri ya da kayıt zinciri” olarak geçmektedir. Blockchain ilk olarak 2008 yılında Satoshi Nakamoto adlı kişi ya da kişiler tarafindan yazılan; "Bitcoin: Peer to Peer Electronic Cash System ("Bitcoin: Kişiden Kişiye Elektronik Para Sistemi)" isimli bir makale ile gündeme gelmiştir (Nakamoto, 2009). Satoshi Nakamoto'nun kim ya da kimler olduğu, hangi milletten olduğu şu an bilinmemekle birlikte konuyla ilgili birçok spekülasyon ve iddia da mevcuttur.

Blockchain, hükümet ya da banka gibi bir aracı kurumun onayı gerekmeksizin insanlar arasındaki değer değişimine olanak sağlayan bir teknolojidir ve merkezi olmayan sanal bir 
defterde kayıtlı olan bu değerler; para birimleri, unvanlar, kimlik bilgileri, özgeçmişler, sözleşmeler ve kişisel veriler olabilmektedir (Bridgers, 2017:3).

Blockchain ayrıca, Bitcoin ve diğer sanal para birimlerinin dayanmış olduğu, açık kaynaklı ve iki taraf arasındaki işlemleri kalıcı, sürekli ve doğrulanabilir bir şekilde kaydeden teknolojidir (Iansiti ve Lakhani, 2017: 120). Bu teknoloji özellikle Bitcoin kavramı ortaya çıkıp, çok fazla popülerlik kazanmaya başladıktan sonra yaygınlaşmaya başlamış ve Bitcoin'in altında yatan teknoloji olmasından dolayı merak konusu haline gelmiştir.

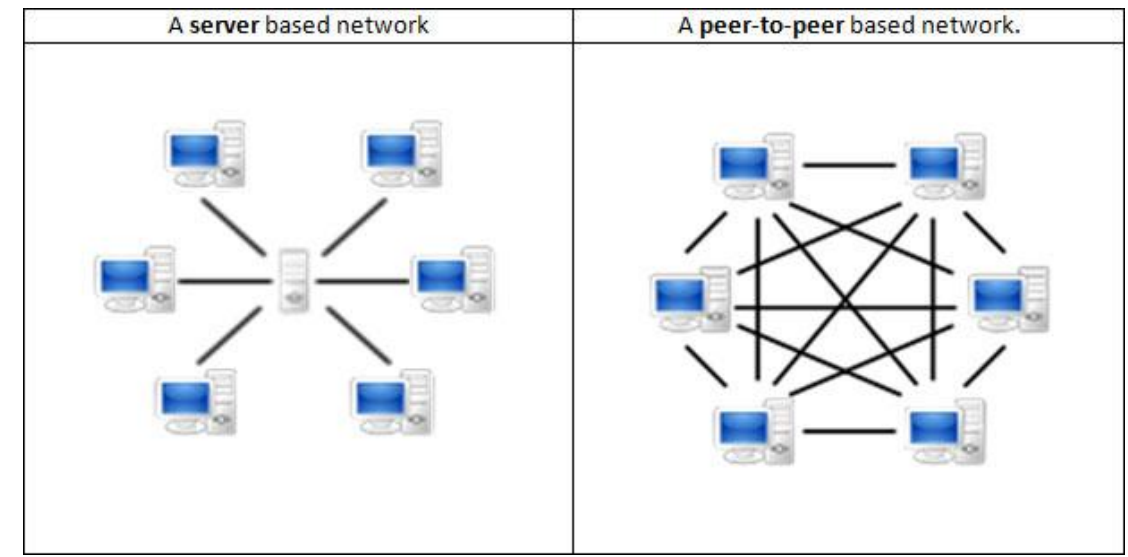

Kaynak: https://www.gigatribe.com/en/help-p2p-intro

Şekil 1. Sunucu tabanlı ve eşten eşe tabanlı sistemler

Şekil 1'de görüldüğü üzere server/sunucu sistemlerinde tek bir merkezden tüm işlemler gerçekleştirilirken; Blockchain sistemindeki ağ veri tabanı yapısı çok daha farklıdır. $\mathrm{Bu}$ sistemde veri tek bir merkezde değil, tüm kullanıcıların makineleri üzerinde bulunur. Blockchain sisteminde tüm bu işlemlerin kriptolu (şifreli) gerçekleştiriliyor olması da sistemi son derece güvenli hale getirmektedir (Europen Central Bank, 2012 https://www.ecb.europa.eu/pub/pdf/other/virtualcurrencyschemes 201210en. pdf, Erişim tarihi: 02.12.2017).

Kripto para birimleri ise, bir elektronik para çeşidi olup, dünya çapında elektronik işlemler için kullanılmaktadır ve kripto para birimleri ile elektronik para birimlerinin birbirinden farklı özellikleri bulunmaktadır. Elektronik para, elektronik olarak saklanan, bir ödeme aracı olarak kabul edilen ve geleneksel para tanımında da olduğu gibi yasal bir dayanağı olan ve Dolar veya Euro hesabı gibi isimlerle adlandırılan para birimleridir. Kripto para birimlerinde ise bu hesap isimleri sanal bir isme dönüşür ve Bitcoin ya da Linden Dollars gibi isimler alır (Europen Central Bank, 2012, https://www.ecb.europa.eu/pub/pdf/other/virtualcurrencyschemes201210en.pdf, Erişim tarihi: 02.12.2017).

Açık kaynak kullanımı ilkeleri ve uçtan uca bir ağ sistemine dayanan kripto para birimleri, herhangi bir merkezden yönetilmeme, sosyal dayanışmayı artırma ve finansal aracı kurumları ortadan kaldırma gibi özellikleri ile geleneksel anlamdaki finansal sektörü aksatıcı bir özelliğe sahiptir (Scott, Loonam ve Kumar, 2017: 423). Bilindiği üzere bir finansal sistem, fon arz ve talep edenler, finansal araçlar, aracı kurumlar ve yasal ve kurumsal 
düzenlemelerden oluşmaktadır. $\mathrm{Bu}$ unsurlardan her biri finansal sistemin ve finansal piyasaların sağlıklı bir şekilde işlemesini sağlar. Bu unsurlardan birinde ya da bir kaçındaki aksama ya da herhangi birinin sistem içerisinde var olmaması sistemin işleyişini olumsuz şeklide etkileyecektir. Bu noktada kripto para birimlerinin bazı özellikleri klasik anlamdaki finansal sistem ile çatışmaktadır. Özellikle merkezi bir otorite tarafından yönetilmeme, denetime tabi olmama ve aracı kurumları ortadan kaldırma gibi özellikleri finansal sistemin etkin bir şekilde işlemesine engel olacak özelliklerdir.

Sanal bir para olan kripto para birimleri, kullanıcılarına bir bankaya ya da merkezi bir otoriteye gitmeden, istenilen anda ve istenilen yerde minimum işlem ücretleri ile ödeme imkanı sunan ve bir merkezi olmayan dijital varlıklardır (Isa, 2017:1). Merkezi olmamalarından dolayı siyasi bir mekanizma tarafindan da kontrol edilemeyen ve işlem amaçlı kullanılabilen kripto paralar, kullanımda oldukları sürece sınırlı bir miktar üzerinden işlem göreceklerdir. Kıt bir kaynak yapısına sahip olmasına rağmen bir değişim aracı olarak kullanılabilme özelliğine sahip bu para birimleri, insanlar tarafından çok değerli varlıklar olarak algılanmaya başlamıştır. Kripto paraların yüksek işlem hacimleri nedeniyle likiditelerinin yüksek olması, yatırımcılar tarafından bir firsat olarak algılanmakta olup bağımsız varlık sınıfına girmeye başlamışlardır (Sontakke ve Ghaisas, 2017: 11).

Kripto paraların en popülerleri Bitcoin ve Ethereum olarak bilinse de, diğer popüler kripto para birimleri ise; Ripple, Stellar, Litecoin, Bitcoin Cash, Synereo, TheDAO, Monero, Augur, Ethereum-Classic, Storjcoin-X, Dash, Steem, NEM, NEO, Cardano, MaidSafeCoin, DigixDAO, Factom, Lisk, DogeCoin, Bitcrystals, Waves, Nxt, Emercoin ve Counterpary'dir (www.kriptopara.org, Erişim tarihi: 02.12.2017).

Bitcoin ise, en basit tanımıyla dijital bir para birimidir. 2008 y1lında Satoshi Nakamoto adında bir kişi ya da grup konu ile ilgili bir makale yayınlamış ve 2009 yılında da ilk uygulaması gerçekleştirilmiştir. Kripto para birimleri ile ilgili akademik çalışmalar literatürde bulunmaktadır. Fakat 2009 yılında merkezi bir otorite tarafından kontrol edilmeyen bir kripto para birimi olan Bitcoin insanların ilgisini çekmiş ve sonrasında diğer kripto para birimleri daha çok merak konusu haline gelmiştir (Narayanan ve Miller, 2017:49). Bitcoin, kripto paraların ilki, en popüleri, en çok işlem göreni ve en büyük parasal hacme sahip olanıdır.

Geleneksel para birimleri altın ya da gümüşe dayanırken, Bitcoin matematiğe dayanmakta, dünyanın her yerinden insanlar yazılım programları aracılığıyla matematiksel bir formül kullanarak bitcoin üretebilmektedir. Ayrıca, yazılım programının açık kaynaklı olması nedeniyle herkes tarafından ulaşılabilir ve kontrol edilebilir niteliktedir (Sharma, 2017: 54).

Bitcoin'in, herhangi merkezi bir otorite tarafindan kontrol edilmemesi, bankalarda hesap açma ya da ödeme yapmadan ve isim, adres ya da diğer kişisel bilgilere gerek kalmadan kullanımının mümkün olması, tamamen şeffaf olması, işlem ücretlerinin oldukça düşük olması ve çok hızlı bir sistem olması onu diğer para birimlerinden ayırmaktadır (Sharma, 2017: 57).

Bitcoin ve diğer kripto para birimleri, geleneksel para birimleri gibi bazı piyasalarda alınıp satılabilirler. $\mathrm{Bu}$ işlemleri yapabilmek için öncelikle alım satımın gerçekleştiği piyasalara yani alım satım işlemlerinin gerçekleştiği web sitelerine üyelik gerekir. Üye olduktan sonra ise, işlem gerçekleştirebilmek için açılan hesabın onaylanması gereklidir. 
Onay işleminden sonra, alım satım yapabilmek için hesaba para gönderilir ve hesap aktif olarak kullanılmaya başlar.

Bir yatırımcının Bitcoine sahip olduğunu kanıtlayan sistem Blockchaine dayanmaktadır ve Bitcoin'in alım satımı sanal cüzdanlar aracılığıyla gerçekleşmesine rağmen gerçek anlamda bu cüzdanlar Bitcoin içermemektedir (Dwyer, 2015: 82). Sanal paraların alım satımının yapılabileceği birçok platform bulunmaktadır ve hesaba para gönderilip hesap onaylandıktan sonra, bu piyasalarda işlem gören her türlü sanal para birimi bu hesaplar üzerinden alınıp satılabilir. Açılan hesaplar, sanal cüzdan olarak adlandırılmakta ve her sanal cüzdanın bir kodu bulunmaktadır.

Geleneksel bankacılık sisteminde hesap numarası ne ise, sanal cüzdandaki kod da aynı işlevi görmektedir. Üye olunan her web sitesi için bir sanal cüzdan oluşturulmakta ve bir kod verilmektedir. Geleneksel bankacılık sisteminden farkı ise, yanlışlıkla yapılan bir işlemin bu platformlarda geri alınamamasıdır.

Kripto paraların sadece olumlu yönleri olduğu düşünülmekle birlikte bu doğru değildir. Bitcoin'in para aklama ya da uyuşturucu kaçakçılığı gibi yasadışı amaçlarla kullanılması, dünyada suça ilişskin faaliyetleri kolaylaştırmakla kalmamış aynı zamanda yapılan işlemlerde güvenlik eksiklerine de yol açmıştır. Bu nedenle Bitcoin'in olumsuz anlamdaki bu hızlı gelişimi onu eleştirilere açık hale getirmiştir (Singh, 2015: 40).

\section{VERI SETI VE YÖNTEM}

\section{1. Çalışmanın Amacı}

Çalışmanın amacı, Bitcoin ve alt koinlerin fiyat hareketlerinin birbiri üzerindeki etkisinin araştırılmasıdır. Çalışmaya konu olan kripto paralar Bitcoin başta olmak üzere Ethereum, Ripple, Bitcoin Cash, Cardano, Litecoin, NEM, NEO, Stellar ve IOTA'dır. Bu kripto paraların seçilmesinin nedeni, çalışmaya konu olan tarihler arasında en yüksek piyasa değerine sahip olmalarıdır. Yatırımcıların alternatif bir yatırım aracı olarak ilgi gösterdikleri kripto paraların fiyat hareketleri arasındaki ilişkinin incelenmesi çalışmanın amacını oluşturmaktadır. Bitcoin ve alt koinlerin fiyat hareketleri arasındaki ilişkinin tespiti, işlem yapanlar açısından belirsizlik ve riski azaltıcı bir etki yapabilir.

\subsection{Veri Seti}

Çalışmada, Bitcoin, Ethereum, Ripple, Bitcoin Cash, Cardano, Litecoin, NEM, NEO, Stellar ve IOTA kripto para birimlerinin fiyat hareketleri arasındaki ilişki incelenmiştir. Çalışmada 15.12.2017 ve 17.1.2018 tarihleri arasında elde edilen 34 adet günlük gözlem verileri kullanılmıştır. Çalışmaya konu olan kripto paralar, piyasa değerleri dikkate alınarak en yüksek piyasa değerine sahip olan 10 kripto para seçilmiştir. Çalışmanın 34 günlük bir süreyi kapsamasının nedeni, Cardano, Litecoin, NEM, NEO, Stellar ve IOTA kripto para birimlerinin verilerine 15.12.2017 tarihinden itibaren ulaşılabiliyor olmasıdır. Çalışmanın veri seti, belirtilen kripto paraların dolar bazındaki kapanış fiyatları dikkate alınarak oluşturulmuştur ve bu kapanış fiyatları https://tr.investing.com internet adresinden elde edilmiştir. Çalışmada kullanılan kripto paralar, sembolleri, toplam piyasa değerleri, fiyatları ve dolaşımdaki sayıları Tablo 1'de belirtilmiştir. 
Tablo 1. Çalışmada Kullanılan Kripto Paraların Piyasa Değerleri, Fiyatları ve Dolaşımdaki Koin Sayısı

\begin{tabular}{|c|c|c|c|c|c|}
\hline & $\begin{array}{c}\text { Kripto } \\
\text { Para }\end{array}$ & Sembol & $\begin{array}{c}\text { Toplam Piyasa } \\
\text { Dĕgeri (USD) }\end{array}$ & Fiyat (USD) & $\begin{array}{c}\text { Dolaşımdaki Koin } \\
\text { Sayısı }\end{array}$ \\
\hline 1 & Bitcoin & BTC & 238.686 .792 .154 & $\underline{14.203,50}$ & $\underline{16,804,787}$ \\
\hline 2 & Ethereum & ETH & 128.931 .804 .060 & $\underline{1.329,20}$ & $\underline{96.999 .552}$ \\
\hline 3 & Ripple & XRP & 69.633 .221 .811 & $\underline{1,80}$ & $\underline{\underline{38.739 .142 .811}} *$ \\
\hline 4 & Bitcoin Cash & BCH & 41.724 .897 .123 & $\underline{2.466,96}$ & $\underline{16.913 .488}$ \\
\hline 5 & Cardano & ADA & 21.089 .934 .769 & $\underline{0.813433}$ & $\underline{\underline{25.927 .070 .538}} *$ \\
\hline 6 & Litecoin & LTC & 13.042 .558 .255 & $\underline{238,13}$ & $\underline{54.771 .208}$ \\
\hline 7 & NEM & XEM & 12.848 .039 .999 & $\underline{1,43}$ & $\underline{8.999 .999 .999} *$ \\
\hline 8 & NEO & NEO & 12.400 .180 .000 & $\underline{190,77}$ & $\underline{\underline{65.000 .000}} *$ \\
\hline 9 & Stellar & XLM & 11.192 .145 .332 & $\underline{0,625589}$ & $\underline{17.890 .572 .456} *$ \\
\hline 10 & IOTA & MIOTA & 9.960 .530 .155 & $\underline{3,58}$ & $\underline{\underline{2.779 .530 .283}} *$ \\
\hline
\end{tabular}

*Madenciliği yok

Kaynak: https://coinmarketcap.com/all/views/all/\# Erişim tarihi: 15.1.2017.

Grafik 1. Kripto Paralar ve Toplam Piyasa Değerleri

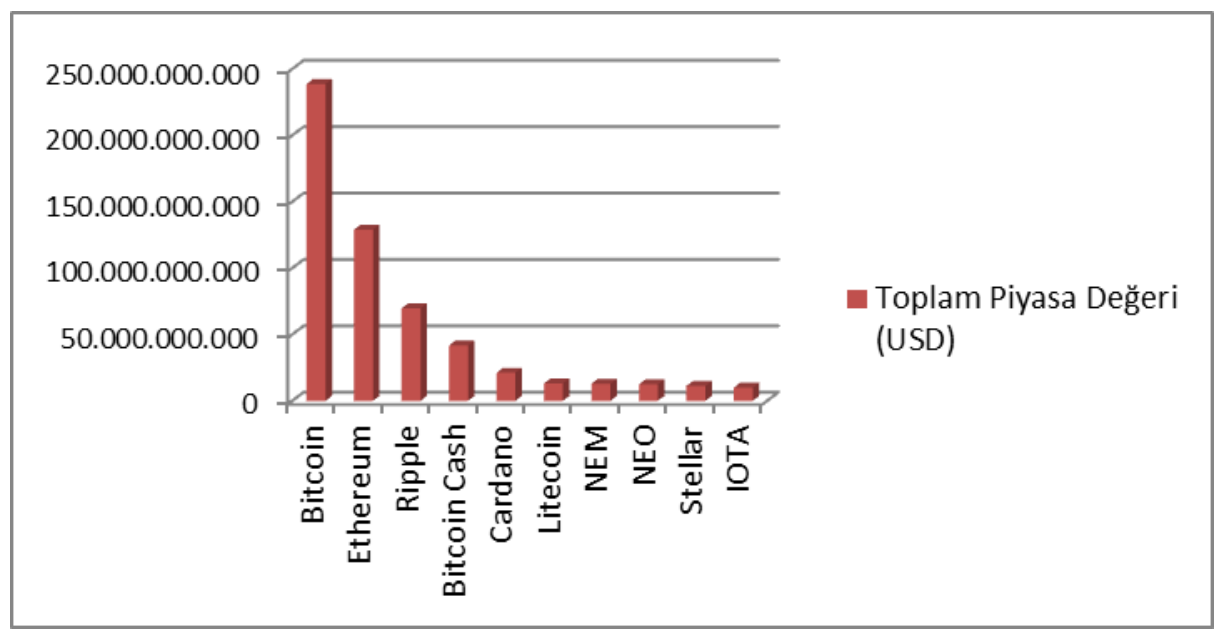

Grafik 1. incelendiğinde Bitcoin'in diğer kripto paralara göre toplam piyasa değeri oldukça yüksektir. Ethereum, Ripple ve Bitcoin Cash ise Bitcoin'i takip etmektedir. Cardano, Litecoin, NEM, NEO, Stellar ve IOTA'nın piyasa değerleri ise diğer kripto paralara ve özellikle Bitcoin'e göre oldukça düşüktür. Bunun en önemli sebebi ise, bu kripto paraların diğerlerine göre oldukça sonra işlem görmeye başlamasıdır.

Başta Bitcoin olmak üzere kripto paralara olan ilgi ve yatırımcıların yaptığı işlemler ve buna bağlı olarak da kripto para çeşitleri ve işlemlerin gerçekleştiği piyasalar da gün geçtikçe 
artmaktadır. Bu günlerde yaklaşık olarak 1615 adet kripto para bulunmaktadır (https://tr.investing.com/crypto/currencies, Erişim tarihi: 17.1.2018). Farkl piyasalarda farklı olarak fiyatlanan kripto paraların arasında piyasa bazında çok büyük farklılıklar bulunmamaktır. Çalışmada kullanılan veriler ise, en yüksek işlem hacmine sahip olması nedeniyle Bitfinex’ten temin edilmiştir.

\subsection{Yöntem}

Çalışmada, araştırmaya konu olan değişkenlerin fiyatları arasındaki ilişkiyi incelemek için serilere Johansen Eşbütünleşme Testi ve Granger Nedensellik Testi uygulanmıştır. Johansen Eşbütünleşme Testini uygulayabilmek için, kullanılacak olan zaman serilerinin aynı seviyede durağan olmaları gerekmektedir. Bu nedenle, serilere birim kök testleri uygulanarak, seriler aynı seviyede durağan hale getirilir. Bir başka deyişle, serilerin birim kök taşıyıp taşımadığının kontrol edilmesi gerekmektedir (Garnger ve Clive, 1969: 425). Seriler aynı seviyede durağan değil ise, serilere Eşbütünleşme Testi uygulanamaz. Durağan olmayan serilere Eşbütünleşme Testi uygulandığı zaman, sahte regresyonlar ortaya çıkabilmektedir (Granger, 1974: 114). Birim kök testinden sonra ise, gecikme uzunluğu belirlenip, Johansen Eşbütünleşme Testi uygulanmaktadır. Seriler arasındaki nedenselliği test eden yaklaşımlardan biri olan Granger Nedensellik Testi'nde ise, $X$ 'in gecikmeli değerleri Y'nin değerlerinin tahmin edilmesine yardımc oluyorsa, 'X, Y'nin Granger nedenidir' diye yorumlanır (Demirci ve Savaş, 2017: 46).

\section{ANALIZ VE AMPIRIIK BULGULAR}

Çalışmada kullanılan serilerin durağan olup olmadığını görmek için, serilere Augmented Dickey-Fuller ve Philips-Perron Birim Kök Testi uygulanmıştır ve test sonuçları Tablo 2 ve Tablo 3'te belirtilmiştir.

Tablo 2. Augmented Dickey-Fuller Birim Kök Testi Sonuçları

\begin{tabular}{|c|c|c|c|}
\hline \multirow[b]{2}{*}{ Değişkenler } & \multicolumn{3}{|c|}{ Düzey Hali } \\
\hline & $\begin{array}{c}\text { None } \\
\text { (olasilik) } \\
\text { [gecikme uz. ] }\end{array}$ & $\begin{array}{c}\text { Intercept } \\
\text { (olasilik) } \\
\text { [gecilkme uz. ] }\end{array}$ & $\begin{array}{c}\text { Trend ve Intercept } \\
\text { (olasilik) } \\
\text { [gecikme uz.] }\end{array}$ \\
\hline BTC & $\begin{array}{c}-1.153123 \\
(0.2226) \\
{[0]}\end{array}$ & $\begin{array}{c}-1.374470 \\
(0.5826) \\
{[0]}\end{array}$ & $\begin{array}{c}-1.940643 \\
(0.6109) \\
{[0]}\end{array}$ \\
\hline ETH & $\begin{array}{c}0.408930 \\
(0.7957) \\
{[0]}\end{array}$ & $\begin{array}{c}-1.189963 \\
(0.6669) \\
{[0]}\end{array}$ & $\begin{array}{c}-1.997531 \\
(0.5805) \\
{[1]}\end{array}$ \\
\hline XRP & $\begin{array}{c}-0.109310 \\
(0.6386) \\
{[0]}\end{array}$ & $\begin{array}{c}-1.346612 \\
(0.5959) \\
{[0]}\end{array}$ & $\begin{array}{c}-0.331161 \\
(0.9862) \\
{[0]}\end{array}$ \\
\hline $\mathrm{BCH}$ & $\begin{array}{c}-0.410408 \\
(0.5278) \\
{[0]}\end{array}$ & $\begin{array}{c}-2.711748 \\
(0.0828) \\
{[0]}\end{array}$ & $\begin{array}{c}-2.814002 \\
(0.2025) \\
{[0]}\end{array}$ \\
\hline $\mathrm{ADA}$ & $\begin{array}{c}-0.002959 \\
(0.6745) \\
{[0]}\end{array}$ & $\begin{array}{c}-1.949164 \\
(0.3068) \\
{[0]}\end{array}$ & $\begin{array}{c}-1.250227 \\
(0.8827) \\
{[0]}\end{array}$ \\
\hline LTC & $\begin{array}{c}-1.126625 \\
(0.2309) \\
{[0]}\end{array}$ & $\begin{array}{c}-1.066186 \\
(0.7172) \\
{[0]}\end{array}$ & $\begin{array}{c}-2.439467 \\
(0.3540) \\
{[0]}\end{array}$ \\
\hline XEM & -0.154200 & -1.937122 & -1.325037 \\
\hline
\end{tabular}




\begin{tabular}{|c|c|c|c|}
\hline & $\begin{array}{c}(0.6228) \\
{[0]}\end{array}$ & $\begin{array}{c}(0.3120) \\
{[0]}\end{array}$ & $\begin{array}{c}(0.8638) \\
{[0]}\end{array}$ \\
\hline NEO & $\begin{array}{c}2.004776 \\
(0.9870) \\
{[5]}\end{array}$ & $\begin{array}{c}1.863756 \\
(0.9996) \\
{[4]}\end{array}$ & $\begin{array}{c}-0.720638 \\
(0.9618) \\
{[4]}\end{array}$ \\
\hline XLM & $\begin{array}{c}-0.122587 \\
(0.6339) \\
{[0]}\end{array}$ & $\begin{array}{c}-1.517033 \\
(0.5127) \\
{[0]}\end{array}$ & $\begin{array}{c}-1.570571 \\
(0.7830) \\
{[0]}\end{array}$ \\
\hline \multirow[t]{2}{*}{ MIOTA } & $\begin{array}{c}-0.739073 \\
(0.3886) \\
{[0]}\end{array}$ & $\begin{array}{c}-2.062110 \\
(0.2605) \\
{[0]}\end{array}$ & $\begin{array}{c}-2.603982 \\
(0.2810) \\
{[0]}\end{array}$ \\
\hline & \multicolumn{3}{|c|}{ Birinci Düzey Hali } \\
\hline Değişkenler & $\begin{array}{c}\text { None } \\
\text { (olasilik) } \\
\text { [gecikme uz.] }\end{array}$ & $\begin{array}{c}\text { Intercept } \\
\text { (olasilik) } \\
\text { [gecikme uz.] }\end{array}$ & $\begin{array}{c}\text { Trend ve Intercept } \\
\text { (olasilik) } \\
\text { [gecikme uz. ] }\end{array}$ \\
\hline BTC & $\begin{array}{c}-6.035919 \\
(0.0000) \\
{[0]}\end{array}$ & $\begin{array}{c}-6.254771 \\
(0.0000) \\
{[0]}\end{array}$ & $\begin{array}{c}-6.126052 \\
(0.0001) \\
{[0]}\end{array}$ \\
\hline ETH & $\begin{array}{c}-4.821790 \\
(0.0000) \\
{[0]}\end{array}$ & $\begin{array}{c}-4.811951 \\
(0.0005) \\
{[0]}\end{array}$ & $\begin{array}{c}-4.765111 \\
(0.0030) \\
{[0]}\end{array}$ \\
\hline XRP & $\begin{array}{c}-5.030726 \\
(0.0000) \\
{[0]}\end{array}$ & $\begin{array}{c}-4.977348 \\
(0.0003) \\
{[0]}\end{array}$ & $\begin{array}{c}-5.325592 \\
(0.0007) \\
{[0]}\end{array}$ \\
\hline $\mathrm{BCH}$ & $\begin{array}{c}-5.954439 \\
(0.0000) \\
{[0]}\end{array}$ & $\begin{array}{c}-5.857632 \\
(0.0000) \\
{[0]}\end{array}$ & $\begin{array}{c}-6.124889 \\
(0.0001) \\
{[0]}\end{array}$ \\
\hline $\mathrm{ADA}$ & $\begin{array}{c}-5.069817 \\
(0.0000) \\
{[0]}\end{array}$ & $\begin{array}{c}-4.992549 \\
(0.0003) \\
{[0]}\end{array}$ & $\begin{array}{c}-4.273277 \\
(0.0017) \\
{[0]}\end{array}$ \\
\hline LTC & $\begin{array}{c}-6.112022 \\
(0.0000) \\
{[0]}\end{array}$ & $\begin{array}{c}-6.233023 \\
(0.0000) \\
{[0]}\end{array}$ & $\begin{array}{c}-6.171101 \\
(0.0001) \\
{[0]}\end{array}$ \\
\hline XEM & $\begin{array}{c}-6.160723 \\
(0.0000) \\
{[0]}\end{array}$ & $\begin{array}{c}-6.082260 \\
(0.0000) \\
{[0]}\end{array}$ & $\begin{array}{c}-6.378725 \\
(0.0000) \\
{[0]}\end{array}$ \\
\hline NEO & $\begin{array}{c}-1.645308 \\
(0.0934) \\
{[4]}\end{array}$ & $\begin{array}{c}-2.240731 \\
(0.1973) \\
{[4]}\end{array}$ & $\begin{array}{c}-5.772622 \\
(0.0003) \\
{[3]}\end{array}$ \\
\hline XLM & $\begin{array}{c}-5.953362 \\
(0.0000) \\
{[0]}\end{array}$ & $\begin{array}{c}-5.903558 \\
(0.0000) \\
{[0]}\end{array}$ & $\begin{array}{c}-5.876461 \\
(0.0002) \\
{[0]}\end{array}$ \\
\hline MIOTA & $\begin{array}{c}-5.724478 \\
(0.0000) \\
{[0]}\end{array}$ & $\begin{array}{c}-5.653927 \\
(0.0000) \\
{[0]}\end{array}$ & $\begin{array}{c}-5.713919 \\
(0.0003) \\
{[0]}\end{array}$ \\
\hline
\end{tabular}

Not: ADF \%5 anlamlılık düzeyi -1.9516

( ) prob. değerini, [ ] gecikme uzunluğunu göstermektedir.

Tablo 3. Philips-Perron Birim Kök Testi Sonuçları

\begin{tabular}{|c|c|c|c|}
\hline & \multicolumn{3}{|c|}{ Düzey Hali } \\
\hline Değişkenler & $\begin{array}{c}\text { None } \\
\text { (olasilık) }\end{array}$ & $\begin{array}{c}\text { Intercept } \\
\text { (olas1lk) }\end{array}$ & $\begin{array}{c}\text { Trend ve Intercept } \\
\text { (olasılı) }\end{array}$ \\
\hline \multirow{2}{*}{ BTC } & -1.187718 & -1.352591 & -2.079451 \\
& $(0.2100)$ & $(0.5931)$ & $(0.5377)$ \\
\hline \multirow{2}{*}{ ETH } & 0.378537 & -1.258470 & -1.803838 \\
& $(0.7878)$ & $(0.6368)$ & $(0.6800)$ \\
\hline
\end{tabular}




\begin{tabular}{|c|c|c|c|}
\hline XRP & $\begin{array}{l}-0.154607 \\
(0.6227)\end{array}$ & $\begin{array}{l}-1.390275 \\
(0.5750)\end{array}$ & $\begin{array}{l}-0.354523 \\
(0.9853)\end{array}$ \\
\hline $\mathrm{BCH}$ & $\begin{array}{c}-0.367193 \\
(0.5445)\end{array}$ & $\begin{array}{c}-2.700077 \\
(0.0847)\end{array}$ & $\begin{array}{c}-2.378440 \\
(0.3833)\end{array}$ \\
\hline $\mathrm{ADA}$ & $\begin{array}{l}-0.075376 \\
(0.6502)\end{array}$ & $\begin{array}{l}-2.024925 \\
(0.2752)\end{array}$ & $\begin{array}{c}-1.581370 \\
(0.7787)\end{array}$ \\
\hline LTC & $\begin{array}{c}-1.435845 \\
(0.1382)\end{array}$ & $\begin{array}{c}-0.835533 \\
(0.7956)\end{array}$ & $\begin{array}{c}-2.439467 \\
(0.3540)\end{array}$ \\
\hline XEM & $\begin{array}{c}-0.121530 \\
(0.6343)\end{array}$ & $\begin{array}{c}-1.912292 \\
(0.3228)\end{array}$ & $\begin{array}{c}-1.250492 \\
(0.8827)\end{array}$ \\
\hline NEO & $\begin{array}{l}1.813888 \\
(0.9810)\end{array}$ & $\begin{array}{c}-0.875924 \\
(0.7832)\end{array}$ & $\begin{array}{c}-2.423483 \\
(0.3615)\end{array}$ \\
\hline XLM & $\begin{array}{c}-0.122587 \\
(0.6339)\end{array}$ & $\begin{array}{c}-1.504167 \\
(0.5191)\end{array}$ & $\begin{array}{c}-1.654400 \\
(0.7486)\end{array}$ \\
\hline \multirow[t]{2}{*}{ MIOTA } & $\begin{array}{c}-0.932810 \\
(0.3053)\end{array}$ & $\begin{array}{c}-1.886685 \\
(0.3342)\end{array}$ & $\begin{array}{c}-2.244425 \\
(0.4509)\end{array}$ \\
\hline & \multicolumn{3}{|c|}{ Birinci Düzey Hali } \\
\hline Değişkenler & $\begin{array}{l}\text { None } \\
\text { (olasilık) }\end{array}$ & $\begin{array}{l}\text { Intercept } \\
\text { (olasilık) }\end{array}$ & $\begin{array}{l}\text { Trend ve Intercept } \\
\text { (olasilık) }\end{array}$ \\
\hline BTC & $\begin{array}{c}-6.009434 \\
(0.0000)\end{array}$ & $\begin{array}{l}-6.226875 \\
(0.0000)\end{array}$ & $\begin{array}{c}-6.104743 \\
(0.0001)\end{array}$ \\
\hline ETH & $\begin{array}{c}-4.769822 \\
(0.0000)\end{array}$ & $\begin{array}{l}-4.749515 \\
(0.0006)\end{array}$ & $\begin{array}{l}-4.701597 \\
(0.0035)\end{array}$ \\
\hline XRP & $\begin{array}{c}-5.033735 \\
(0.0000)\end{array}$ & $\begin{array}{c}-4.979027 \\
(0.0003)\end{array}$ & $\begin{array}{c}-5.325592 \\
(0.0007)\end{array}$ \\
\hline $\mathrm{BCH}$ & $\begin{array}{c}-6.027688 \\
(0.0000)\end{array}$ & $\begin{array}{c}-5.919245 \\
(0.0000)\end{array}$ & $\begin{array}{c}-6.470722 \\
(0.0000)\end{array}$ \\
\hline $\mathrm{ADA}$ & $\begin{array}{c}-5.065695 \\
(0.0000)\end{array}$ & $\begin{array}{c}-4.983403 \\
(0.0003)\end{array}$ & $\begin{array}{c}-4.968189 \\
(0.0018)\end{array}$ \\
\hline LTC & $\begin{array}{c}-6.123986 \\
(0.0000)\end{array}$ & $\begin{array}{l}-6.556215 \\
(0.0000)\end{array}$ & $\begin{array}{c}-6.337838 \\
(0.0001)\end{array}$ \\
\hline XEM & $\begin{array}{c}-6.162074 \\
(0.0000)\end{array}$ & $\begin{array}{c}-6.083430 \\
(0.0000)\end{array}$ & $\begin{array}{c}-6.378725 \\
(0.0000)\end{array}$ \\
\hline NEO & $\begin{array}{c}-5.179864 \\
(0.0000)\end{array}$ & $\begin{array}{c}-6.559562 \\
(0.0000)\end{array}$ & $\begin{array}{c}-6.597516 \\
(0.0000)\end{array}$ \\
\hline XLM & $\begin{array}{c}-5.954141 \\
(0.0000)\end{array}$ & $\begin{array}{c}-5.903558 \\
(0.0000)\end{array}$ & $\begin{array}{c}-5.876461 \\
(0.0002)\end{array}$ \\
\hline MIOTA & $\begin{array}{c}-6.101337 \\
(0.0000)\end{array}$ & $\begin{array}{c}-6.121380 \\
(0.0000)\end{array}$ & $\begin{array}{c}-6.180332 \\
(0.0001)\end{array}$ \\
\hline
\end{tabular}

Tablo 4. Johansen Eştümleşim Testi Sonuçları

\begin{tabular}{|c|c|c|c|c|}
\hline $\begin{array}{c}\text { Eştümleşim } \\
\text { Sayıs1 }\end{array}$ & $\begin{array}{c}\text { Eigen } \\
\text { Değeri }\end{array}$ & Trace İstatistiği & $\begin{array}{c}0.05 \text { Kritik } \\
\text { Değer }\end{array}$ & Olasılık \\
\hline Yok* & 0.906464 & 349.3702 & 273.1889 & 0.0000 \\
\hline En Çok 1* & 0.893348 & 271.1796 & 228.2979 & 0.0001 \\
\hline En Çok 2* & 0.761758 & 197.3195 & 187.4701 & 0.0142 \\
\hline En Çok 3 & 0.742222 & 149.9820 & 150.5585 & 0.0539 \\
\hline
\end{tabular}

Tablo 4 incelendiğinde, Johansen Eştümleşim Testi sonucunda değişkenler arasında en fazla 3 eştümleşim olduğu görülmektedir. 2 gecikme için uygulanan Johansen Eştümleşim Testi sonucuna göre 0.05 anlamlılık düzeyinde değişkenler arasında en fazla 3 eştümleşim ilişkisinin olduğu tespit edilmiştir. 
Tablo 5. Granger Nedensellik Testi Sonuçları

\begin{tabular}{|c|c|c|}
\hline Sıfir Hipotezi & F İstatistik & Olasılık \\
\hline DBCH DADA'nın Granger nedeni değildir & 0.14489 & 0.8658 \\
\hline DADA DBCH'nin Granger nedeni değildir & 1.19844 & 0.3178 \\
\hline DBTC DADA'nın Granger nedeni değildir & 0.27628 & 0.7608 \\
\hline DADA DBTC'nin Granger nedeni değildir & 1.85350 & 0.1768 \\
\hline DETH DADA'nın Granger nedeni değildir & 0.88565 & 0.4245 \\
\hline DADA DETH'nin Granger nedeni değildir & 0.79202 & 0.4636 \\
\hline DLTC DADA'nın Granger nedeni değildir & 0.05465 & 0.9469 \\
\hline DADA DLTC'nin Granger nedeni değildir & 0.92250 & 0.4101 \\
\hline DMIOTA DADA'nın Granger nedeni değildir & 0.88967 & 0.4229 \\
\hline DADA DMIOTA'nın Granger nedeni değildir & 0.48708 & 0.6199 \\
\hline DNEO DADA'nın Granger nedeni değildir & 1.96501 & 0.1604 \\
\hline DADA DNEO'nun Granger nedeni değildir & 3.96746 & $0.0314 *$ \\
\hline DXEM DADA'nın Granger nedeni değildir & 0.75194 & 0.4814 \\
\hline DADA DXEM'nin Granger nedeni değildir & 0.41795 & 0.6627 \\
\hline DXLM DADA'nın Granger nedeni değildir & 2.29410 & 0.1209 \\
\hline DADA DXLM'nin Granger nedeni değildir & 0.93237 & 0.4064 \\
\hline DXRP DADA'nın Granger nedeni değildir & 0.61126 & 0.5503 \\
\hline DADA DXRP'nin Granger nedeni değildir & 0.11943 & 0.8879 \\
\hline DBTC DBCH'nin Granger nedeni değildir & 3.34139 & $0.0511 *$ \\
\hline DBCH DBTC'nin Granger nedeni değildir & 2.15542 & 0.1361 \\
\hline DETH DBCH'nin Granger nedeni değildir & 0.33083 & 0.7213 \\
\hline DBCH DETH'nin Granger nedeni değildir & 0.27712 & 0.7602 \\
\hline DLTC DBCH'nin Granger nedeni değildir & 4.24495 & $0.0254 *$ \\
\hline DBCH DLTC'nin Granger nedeni değildir & 2.09331 & 0.1436 \\
\hline DMIOTA DBCH'nin Granger nedeni değildir & 3.51153 & 0.0447 \\
\hline DBCH DMIOTA'nın Granger nedeni değildir & 3.43949 & 0.0473 \\
\hline DNEO DBCH'nin Granger nedeni değildir & 0.25038 & 0.7804 \\
\hline DBCH DNEO'nun Granger nedeni değildir & 0.22554 & 0.7996 \\
\hline DXEM DBCH'nin Granger nedeni değildir & 0.85384 & 0.4374 \\
\hline DBCH DXEM'nin Granger nedeni değildir & 0.60247 & 0.5549 \\
\hline DXLM DBCH'nin Granger nedeni değildir & 0.15221 & 0.8596 \\
\hline DBCH DXLM'nin Granger nedeni değildir & 0.27172 & 0.7642 \\
\hline DXRP DBCH'nin Granger nedeni değildir & 1.80092 & 0.1851 \\
\hline DBCH DXRP'nin Granger nedeni değildir & 0.33836 & 0.7160 \\
\hline DETH DBTC'nin Granger nedeni değildir & 0.23895 & 0.7892 \\
\hline
\end{tabular}




\begin{tabular}{|c|c|c|}
\hline DBTC DETH'nin Granger nedeni değildir & 2.35880 & 0.1145 \\
\hline DLTC DBTC'nin Granger nedeni değildir & 1.03486 & 0.3695 \\
\hline DBTC DLTC'nin Granger nedeni değildir & 0.76556 & 0.4753 \\
\hline DMIOTA DBTC'nin Granger nedeni değildir & 0.66858 & 0.5210 \\
\hline DBTC DMIOTA'nın Granger nedeni değildir & 0.33464 & 0.7186 \\
\hline DNEO DBTC'nin Granger nedeni değildir & 1.73856 & 0.1956 \\
\hline DBTC DNEO'nun Granger nedeni değildir & 1.59892 & 0.2214 \\
\hline DXEM DBTC'nin Granger nedeni değildir & 3.62856 & $0.0408 *$ \\
\hline DBTC DXEM'nin Granger nedeni değildir & 0.38024 & 0.6874 \\
\hline DXLM DBTC'nin Granger nedeni değildir & 1.33658 & 0.2802 \\
\hline DBTC DXLM'nin Granger nedeni değildir & 0.26206 & 0.7715 \\
\hline DXRP DBTC'nin Granger nedeni değildir & 6.82282 & $0.0042 *$ \\
\hline DBTC DXRP'nin Granger nedeni değildir & 0.03381 & 0.9668 \\
\hline DLTC DETH'nin Granger nedeni değildir & 2.14866 & 0.1369 \\
\hline DETH DLTC'nin Granger nedeni değildir & 1.01089 & 0.3778 \\
\hline DMIOTA DETH'nin Granger nedeni değildir & 0.64151 & 0.5346 \\
\hline DETH DMIOTA'nın Granger nedeni değildir & 1.38195 & 0.2689 \\
\hline DNEO DETH'nin Granger nedeni değildir & 12.1900 & $0.0002 *$ \\
\hline DETH DNEO'nun Granger nedeni değildir & 4.51227 & $0.0208 *$ \\
\hline DXEM DETH'nin Granger nedeni değildir & 2.32628 & 0.1176 \\
\hline DETH DXEM'nin Granger nedeni değildir & 1.09798 & 0.3485 \\
\hline DXLM DETH'nin Granger nedeni değildir & 0.56963 & 0.5726 \\
\hline DETH DXLM'nin Granger nedeni değildir & 0.86570 & 0.4325 \\
\hline DXRP DETH'nin Granger nedeni değildir & 2.45076 & 0.1059 \\
\hline DETH DXRP'nin Granger nedeni değildir & 0.72766 & 0.4926 \\
\hline DMIOTA DLTC'nin Granger nedeni değildir & 2.09411 & 0.1435 \\
\hline DLTC DMIOTA'nın Granger nedeni değildir & 2.54842 & 0.0976 \\
\hline DNEO DLTC'nin Granger nedeni değildir & 4.03628 & $0.0297 *$ \\
\hline DLTC DNEO'nun Granger nedeni değildir & 3.38144 & $0.0495 *$ \\
\hline DXEM DLTC'nin Granger nedeni değildir & 0.51565 & 0.6031 \\
\hline DLTC DXEM'nin Granger nedeni değildir & 1.23297 & 0.3079 \\
\hline DXLM DLTC'nin Granger nedeni değildir & 0.02934 & 0.9711 \\
\hline DLTC DXLM'nin Granger nedeni değildir & 0.50758 & 0.6078 \\
\hline DXRP DLTC'nin Granger nedeni değildir & 2.39424 & 0.1111 \\
\hline DLTC DXRP'nin Granger nedeni değildir & 0.15105 & 0.8606 \\
\hline DNEO DMIOTA'nın Granger nedeni değildir & 1.39334 & 0.2662 \\
\hline DMIOTA DNEO’nun Granger nedeni değildir & 1.65041 & 0.2115 \\
\hline DXEM DMIOTA'nın Granger nedeni değildir & 0.16787 & 0.8464 \\
\hline DMIOTA DXEM'nin Granger nedeni değildir & 0.22466 & 0.8003 \\
\hline
\end{tabular}




\begin{tabular}{|c|c|c|}
\hline DXLM DMIOTA'nın Granger nedeni değildir & 0.23474 & 0.7924 \\
\hline DMIOTA DXLM'nin Granger nedeni değildir & 0.08924 & 0.9149 \\
\hline DXRP DMIOTA'nın Granger nedeni değildir & 0.59404 & 0.5594 \\
\hline DMIOTA DXRP'nin Granger nedeni değildir & 0.47402 & 0.6278 \\
\hline DXEM DNEO'nun Granger nedeni değildir & 2.50194 & 0.1014 \\
\hline DNEO DXEM'nin Granger nedeni değildir & 3.29838 & 0.0529 \\
\hline DXLM DNEO’nun Granger nedeni değildir & 1.58932 & 0.2233 \\
\hline DNEO DXLM'nin Granger nedeni değildir & 2.39726 & 0.1108 \\
\hline DXRP DNEO'nun Granger nedeni değildir & 2.15476 & 0.1362 \\
\hline DNEO DXRP'nin Granger nedeni değildir & 2.53233 & 0.0989 \\
\hline DXLM DXEM'nin Granger nedeni değildir & 2.53070 & 0.0990 \\
\hline DXEM DXLM'nin Granger nedeni değildir & 5.15416 & $0.0130 *$ \\
\hline DXRP DXEM'nin Granger nedeni değildir & 0.61585 & 0.5479 \\
\hline DXEM DXRP'nin Granger nedeni değildir & 1.07141 & 0.3572 \\
\hline DXRP DXLM'nin Granger nedeni değildir & 0.02500 & 0.9753 \\
\hline DXLM DXRP'nin Granger nedeni değildir & 0.51426 & 0.6039 \\
\hline
\end{tabular}

Granger Nedensellik Testi sonuçlarına göre, \%5 anlamlılık düzeyinde değişkenler arasında altı adet tek yönlü ve iki adet çift yönlü nedensellik ilişkisi tespit edilmiştir. Değişkenlerin çoğunun birbirinin Granger nedeni olmadı görülmektedir. Granger Nedensellik testinin sonuçları aşağıdaki gibidir;

- $\quad$ ADA ve NEO arasında tek yönlü bir ilişki ve ADA'nın NEO'nun Granger nedeni olduğu,

- BTC ve BCH arasında tek yönlü bir ilişki ve BTC'nin BCH'nin Granger nedeni olduğu,

- LTC ve BCH arasında tek yönlü bir ilişki ve LTC'nin BCH'nin Granger nedeni olduğu,

- XEM ve BTC arasında tek yönlü bir ilişki ve XEM'in BTC'nin Granger nedeni olduğu,

- XRP ve BTC arasında tek yönlü bir ilişki ve XRP'nin BTC'nin Granger nedeni olduğu,

- $\quad$ NEO ve ETH arasında çift yönlü bir ilişki ve ikisinin de birbirinin Granger nedeni olduğu,

- $\quad$ NEO ve LTC arasında çift yönlü bir ilişki ve ikisinin de birbirinin Granger nedeni olduğu,

- XEM ve XLM arasında tek yönlü bir ilişki ve XEM'in XLM'nin Granger nedeni olduğu, tespit edilmiştir. 


\section{SONUÇ VE ÖNERILER}

2010 yılında Bitcoin'in piyasalarda işlem görmeye başlamasından sonra, birçok farklı kripto para birimi de bu piyasalarda yerini almıştır. Farklı yatırım alternatifi arayan yatırımcıların oldukça ilgisini çeken bu piyasaların gün geçtikçe sayısı artmakta, işlem gören kripto paralar da buna paralel olarak artış göstermektedir. Bunun yanında kripto paraların işlem hacimleri ve piyasa değerleri de çok hızlı bir şekilde artmaya devam etmektedir.

Tasarruflarını farklı şekillerde değerlendirmek isteyen yatırımcılar ise bunu ya para piyasalarında, ya sermaye piyasalarında ya da kripto para piyasalarında gerçekleştirmektedir. Kripto paraların sadece tek başına değerlendirilerek yatırım yapılması ise yatırımcı açısından pek bir anlam ifade etmemektedir. Bu yüzden bu paraların birbirleri arasındaki etkileşimi önem kazanmaktadır. Yatırımcılar kripto para piyasalarında bir portföy oluştururken seçimlerini bu paralar arasındaki ilişkiyi dikkate alarak yaptıklarında kazançlarını maksimum yapmayı hedeflerler.

$\mathrm{Bu}$ çalışmada en yüksek piyasa değerine ve bunun yanında yüksek işlem hacmine sahip 10 kripto para seçilerek birbirleri arasındaki etkileşim incelenmiştir. Yapılan Johansen Eştümleşim Testi ve Granger Nedensellik Testi sonuçlarına göre de; Cardano'nun NEO'nun Granger nedeni olduğu, Bitcoin'in Bitcoin Cash'in Granger nedeni olduğu, Litecoin'in Bitcoin Cash'in Granger nedeni olduğu, NEM'in Bitcoin Cash'in Granger nedeni olduğu, Ripple'ın Bitcoin'in Granger nedeni olduğu, NEO ve Ethereum'un birbirinin Granger nedeni olduğu, NEO ve Litecoin'in birbirinin Granger nedeni olduğu ve NEM'in Stellar'ın Granger nedeni olduğu tespit edilerek, bu değişkenlerin fiyat hareketlerinin kısa dönemde birbirini etkilediği ortaya konmuştur.

Literatürde Bitcoin ile ilgili az sayıda çalışma görülmektedir. Alt koinlerle ilgili ise 2018 yılında Ciaian'ın çalışması tespit edilmiştir. Çalışmada, Bitcoin ve 16 alt koin arasındaki fiyat hareketleri ilişkisi araştırılmıştır. Sonuçta ilişkinin varlığı tespit edilmiştir. Çalışmamızda, Cianin'ın çalışma sonuçları ile benzer sonuçlara ulaşılmıştır. Bunun dışında Bitcoin ve alt koinlerle ilişskili sonuçların karşılaştırılabileceği bir çalışmaya literatürde rastlanmamıştır. Literatürde Bitcoin ile ilgili diğer çalışmalar, Bitcoin'in farklı para birimleri (Dolar, Euro, Yen vb.), altın ve çeşitli makroekonomik değişkenler arasındaki ilişkisine yönelik çalışmalar saptanmıştır.

Tasarruflarını alternatif bir yatırım aracı olan kripto paralar ile değerlendirmek isteyen yatırımcılar, bu paraların fiyat hareketleri arasındaki ilişkiyi dikkate almak zorundadırlar. Yatırımcılar portföylerini oluştururken risklerini azaltmak için fiyat hareketleri arasında nedensellik ilişkisi bulunan kripto paraları aynı portföye dahil etmemelidirler. $\mathrm{Bu}$ sayede risklerini azaltarak getirilerini arttırma şansına sahip olabilirler.

Çalışmada kullanılan kripto para birimlerinden Cardano, Litecoin, NEM, NEO, Stellar ve IOTA kripto para birimlerinin verilerine 15.12.2017 tarihinden itibaren ulaş1labiliyor olması nedeniyle değişkenler arasındaki ilişki kısa dönem bazında incelenmiştir. Gözlem sayısı artırılarak yapılacak çalışmalar ile literatüre katkı sağlanabilir. 


\section{KAYNAKLAR}

Atik, Murat - Köse, Yaşar - Yılmaz, Bülent - Sağlam, Fatih (2015). "Kripto Para: Bitcoin ve Döviz Kurları Üzerine Etkileri”, Bartın Üniversitesi İktisadi ve İdari Bilimler Fakültesi Dergisi, 6(11), ss. 247-261.

Balc1lar, Mehmet - Bouri, Elie - Gupta, Rangan - Roubaud, David (2017). "Can Volume Predict Bitcoin Returns and Volatility ? A Quantiles-Based Approach”, Economic Modelling, 64, pp. 74-81.

Bridgers, Adam (2017). "Will Workplaces be Going off the Rails 0n the Blockchain?", Journal off Internet Law, 20(11), pp. 3-6.

Ciaian, Pavel - Rajcaniova, Miroslava - Kancs, d'Artis (2018). "Virtual Relationships: Short and Long Run Evidence from Bitcoin and Altcoin Markets", Journal of International Financial Markets, Institutions and Money, 52, pp. 173-195.

Demirci, N. Savaş (2017). "İmalat Sanayi Sektöründe Üretim ve Banka Kredileri İlişkisi: Türkiye İçin Eşbütünleşme ve Nedensellik Analizi”, Dokuz Eylül Üniversitesi Sosyal Bilimler Enstitüsü Dergisi, 19(1), ss.35-61.

Dyhrberg, Anne Haubo (2016). "Bitcoin, Gold and the Dollar, A GARCH Volatility Analysis", Finance Research Letters, 16(2016), pp. 85-92.

Dwyer, Gerald P. (2015). "The Economics of Bitcoin and Similar Private Digital Currencies", Journal of Financial Stability, 17(2015), pp. 81-91.

Granger, Clive W. J. (1969). "Investigating Causal Relations by Econometric Models and Cross-Spectral Methods", Econometrica: Journal of the Econometric Society, 37(3), pp. 424-438.

Granger, C.W.J.- Newbold, P. (1974). "Spurious regression in econometrics", Journal of Econometrics, 2, pp. 111-120.

Iansiti, Marco - Lakhani, Karim R. (2017). "The Truth About Blockchain”, Harvard Business Review, 95(1), pp. 118-127.

https://tr.investing.com/crypto/currencies, Erişim Tarihi: 17.1.2018

Europen Central Bank, (2012). "Virtual Currency Schemes" (https://www. ecb. europa. eu/pub/pdf/other/virtualcurrencyschemes201210en.pdf, Erişim tarihi: 02.12.2017)

Europen Central Bank, (2012), Virtual Currency Schemes, (https://www. ecb.europa.eu/pub/pdf/other/virtualcurrencyschemes201210en.pdf, Erişim tarihi: 02. 12.2017 .

Isa, M. (2017). Speculative Instrument or Game-Changer?. Finweek, pp.18-18. 
Johansen, Soren (1988). "Statistical Analysis of Cointegration Vectors", Journal of Economic Dynamics and Control, 12(2-3), pp. 231-254.

Katsiampa, Paraskevi (2017). "Volatility Estimation for Bitcoin: A Comprasion of GARCH Models", Economics Letters, 158, pp. 3-6.

Kristoufek, Ladislav (2014). "What Are the Main Drivers of the Bitcoin Price? Evidence from Wavelet Coherence Analysis", Cornell University Library, http://arxiv.org/abs/ 14.06.0268, Erişim tarihi: 10.1.2018.

Li, Xin - Wang, Chong Alex (2017). "The Technology and Economic Determinants of Cryptocurrencies Exchange Rates: The case of Bitcoin", Decision Support Systems, 95, pp. 49-60.

www.kriptopara.org, Erişim tarihi: 01.12.2017.

Nakamoto, Satoshi (2009). "Bitcoin: A Peer to Peer Electronic Cash System", https://bitcoin.org/bitcoin.pdf, Erişim tarihi: 15.12.2017

Narayanan, Arvind - Miller, Andrew (2017). "Research for Practice: Cryptocurrincies, Blockchains and Smart Contracts: Hardware for Deep Learning", Communications of the ACM, 60(5), pp. 48-51.

Sahoo, Pradipta Kumar (2017). "Bitcoin as Digital Money: Its Growth and Future Sustainability", Theoretical and Applied Economics, 24(4-613), pp. 53-64.

Scott, Brett - Loonam, John - Kumar, Vikas (2017). "Exploring the Rising Blockchain Technology: Towards Distributed Collaborative Organizations", Strategic Change, 26(5), pp. 423-428.

Sharma, Suksham (2017). “Digital Mints: Know the Factory”, PC Quest, 30(7), pp. 54-57.

Singh, Kavid (2015). "The New Wild west: Preventing Money Laundering in the Bitcoin Network", Northwestern Journal of Technology and Intellectual Property, 13(1), pp. 38-63.

Sontakke, Kaustubh Arvind - Ghaisas, Aishwarya (2017). "Crypto Currencies: A Developing Asset Class", Internatioanal Journal of Business Insight and transformation, 10(2), pp. $10-17$.

Wandhöfer, Ruth (2017). "The future of digital retail payments in Europe: A Place for Digital Cash”, Journal of Payments Strategy\&Systems, 11(3), pp. 248-258. 